\title{
Correction to: A Technology for Assisting Literacy Development in Adults with Dyslexia and Illiterate Second Language Learners
}

Matteo Cristani, Serena Dal Maso, Sabrina Piccinin, Claudio Tomazzoli, Marco Vedovato, and Maria Vender

Correction to:

Chapter "A Technology for Assisting Literacy Development in Adults with Dyslexia and Illiterate Second Language Learners" in: V. L. Uskov et al. (eds.), Smart Education and e-Learning 2021, Smart Innovation, Systems and Technologies 240, https://doi.org/10.1007/978-981-16-2834-4_40

In the original publication of this book, the author's name in the reference number 24 was incorrect in chapter 40. The author's name is corrected from "Eva, M" to "Malessa, E". The erratum chapter and the book have been updated with the change. 